\title{
Rapid Measurement of Diffusion of Gas Through the Skin of Apple Fruits
}

\author{
Michael Knee ${ }^{1}$ \\ Department of Horticulture, The Ohio State University, Columbus, \\ $\mathrm{OH} 43210$
}

Additional index words. Malus domestica, gas exchange, storage atmosphere

Abstract. A method was devised for measuring the resistance to gaseous diffusion of bulky plant organs, such as apple (Malus domestica Borkh.) fruits, in which the skin is the major barrier to diffusion. An individual fruit was incubated in a sealed container in the presence of a measured concentration of ethane for a certain time (usually 20 min). The fruit was then transferred to another, similar container. The ethane concentration that diffused into the new container was measured after an equal time (usually $20 \mathrm{~min}$ ). An expression relating resistance to the measured ethane concentrations was derived from Fick's First Law of diffusion. An estimate of the internal volume of the fruit, accessible to ethane, was also necessary. The method was tested on several fruits of various apple cultivars. Longer incubation periods are necessary for apples with high diffusive resistance.

Effects of the gaseous environment on commodities after harvest are most easily considered in terms of the concentrations of gases surrounding the produce. However, when gases are produced or consumed, particularly for bulky organs such as apples, concentration gradients will exist so that tissues experience internal concentrations that differ from external. Internal concentrations of $\mathrm{O}_{2}$ and $\mathrm{CO}_{2}$ are particularly important for controlled-atmosphere storage; internal ethylene concentrations also need to be considered when fruit is treated with ethylene (Knee et al., 1987) or when ethylene removal during storage is attempted (Dover, 1985).

Direct measurement of internal gas concentrations is usually difficult or inconvenient for apples in atmospheres other than air,

Received for publication 18 June 1990. Salaries and research support provided by state and federal funds appropriated to the Ohio Agricultural Research and Development Center, The Ohio State Univ. Journal Article no. 176-90. I acknowledge helpful advice from Arthur C. Cameron, Michigan State Univ. The cost of publishing this paper was defrayed in part by the payment of page charges. Under postal regulations, this paper therefore must be hereby marked advertisement solely to indicate this fact.

'Professor. and reported results often seem to be erroneous (Knee, 1990). Burg and Burg (1965) proposed that the internal concentration of a gas could be estimated from its rate of production or consumption and the resistance to diffusion of the gas through the skin of the fruit. When the skin is the major barrier, diffusion is represented by Fick's First Law. Cameron and Yang (1982) described a simple and reliable method for measuring diffusive resistance of plant organs that obey a fruit in an atmosphere containing ethane and measurement of the efflux of this gas Fick's Law. The method involves incubating

after transferring the fruit to a container free of ethane. The method is time-consuming since it requires equilibration for several hours during loading and unloading phases, and several chromatographic analyses are performed to establish the efflux kinetics. Banks (1985) developed a more rapid method, involving several measurements in the first few minutes of efflux, but equilibration during loading was still necessary.

While investigating the response of apples to low-oxygen storage, a method was devised to measure diffusive resistance of many individual apples (Knee et al., 1990). A single apple was enclosed in a 1-liter container and $1 \mathrm{ml}$ of ethane was injected. The ethane concentration in the container $\left(\mathrm{C}_{1}\right)$ was measured after $\approx 15 \mathrm{~min}$. At exactly $20 \mathrm{~min}$, the container was opened and the apple transferred to a fresh 1-liter container. Exactly 20 min later, the ethane concentration $\left(\mathrm{C}_{2}\right)$ in the second container was estimated. Ethane was analyzed by gas chromatography on an alumina column $(50 \times 0.4 \mathrm{~cm})$ at $100 \mathrm{C}$ with $\mathrm{N}$ carrier gas at $60 \mathrm{ml} \cdot \mathrm{min}^{-1}$ and a flame ionization detector. Estimates of fruit weight (W) and fruit volume (V) were required for the calculation of diffusive resistance (R). Volume was estimated by water displacement (Hatfield and Knee, 1988).

Diffusion of ethane into an apple during loading is represented by the following equation, derived from Eq. [9] of Cameron and Yang (1982):

$$
\ln \left[1-\frac{C_{i}}{C_{e}}\right]=-k \cdot t \cdot \frac{V_{g}}{V_{o}}
$$

where $C_{1}$ is the internal concentration of ethane

Table 1. Measurement of diffusive resistance of several apple cultivars by Cameron and Yang (1982) method and new method with a range of incubation times.

\begin{tabular}{lcccr}
\hline \hline & \multicolumn{4}{c}{ Diffusive resistance $\left(\mathrm{s} \cdot \mathrm{cm}^{-1}\right)$} \\
\cline { 2 - 5 } Cultivar & Cameron & \multicolumn{3}{c}{ New method, incubation time (rein) } \\
\cline { 2 - 5 } Red Delicious (1) & and Yang & 5 & 10 & 20 \\
Red Delicious (2) & 8,350 & 12,600 & 6,800 & 7,800 \\
Granny Smith & 20,300 & 10,500 & 14,800 & 21,400 \\
Golden Delicious & 36,300 & 5,600 & 15,900 & 24,100 \\
\hline & 8,000 & 6,400 & 7,600 \\
\hline
\end{tabular}

'Data were obtained for two apples of each cultivar. 'Red Delicious' from two sources were tested. Analysis of variance was performed after logarithmic transformation with apples as replicates. The data shown are back-transformed means. The probabilities of null effects in the new method were 0.001 for cultivar, 0.002 for incubation time, and 0.345 for their interaction. The probability of null effect of cultivar in the Cameron and Yang (1982) method was 0.005. 


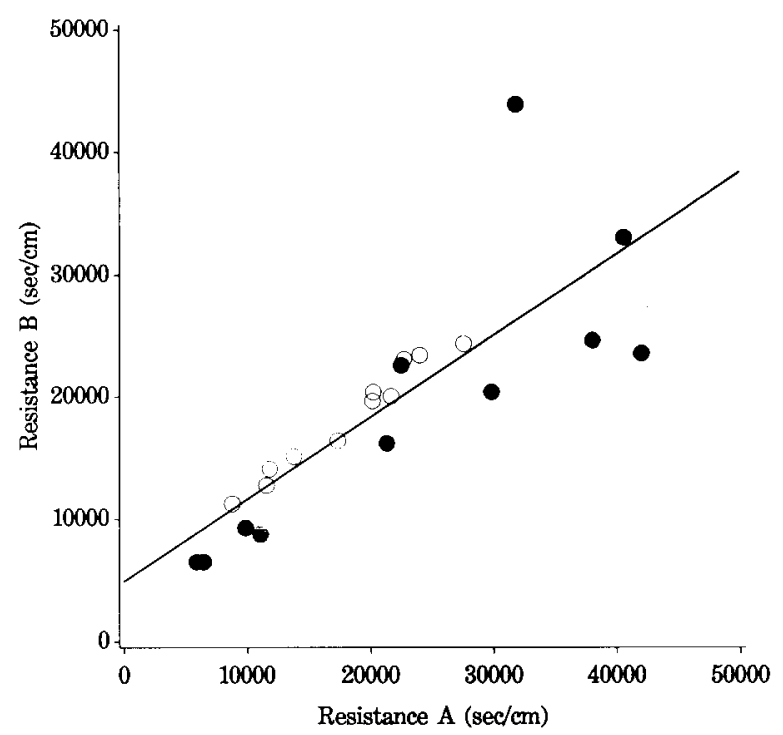

Fig. 1. Comparison of diffusive resistance $\left(\mathrm{s} \cdot \mathrm{cm}^{-1}\right)$ of individual apples measured by Cameron and Yang (1982) method (A) and new method (B). O, 'Cox' apples; $\bigcirc$, other cultivars as shown in Table

1. The fitted line represents the regression $\mathrm{R}_{B}=0.669 . \mathrm{R}_{\mathrm{A}}+4943(r=0.82)$.

at time $\mathrm{t}, \mathrm{C}_{\mathrm{e}}$ is the external concentration at equilibrium, $\mathrm{V}_{\mathrm{g}}$ is the volume of the gas phase, and $\mathrm{V}_{\mathrm{o}}$ is the volume external to the apple. This equation allows for the fact that with a small container, the contribution of the internal gas volume of the apple cannot be neglected and $\mathrm{V}_{\mathrm{o}}$ is significantly less than $\mathrm{V}_{\mathrm{g}}$. Since uptake of ethane by the apple has little effect on the external concentration, $\mathrm{C}_{\mathrm{e}}$ is close to $\mathrm{C}_{1}$. Even in the extreme case of a $300-\mathrm{g}$ apple in a 1-liter container, and estimation of $\mathrm{C}_{1}$ before any ethane had entered the fruit, this approximation was calculated to result in a 7\% error in the estimate of $\mathrm{R}$. Thus, Eq. [1] can be rearranged:

$$
C_{i}=C_{1} \cdot \frac{V_{o}}{V_{g}} \cdot\left(1-e^{-k \cdot t}\right)
$$

Efflux after the same time (t) can be represented by a similar equation:

$$
C_{x} \cdot \frac{V_{o}}{V_{g}} \cdot\left(1-e^{-k \cdot t}\right)
$$

where $\mathcal{I}_{\infty}$. is the external concentration after efflux to equilibrium. However, $\mathrm{C}_{\alpha}$ can also be derived from $C_{i}$ :

$$
\mathrm{C}_{\alpha}=\mathrm{C}_{\mathrm{i}} \cdot \frac{\mathrm{V}_{\mathrm{i}}}{\mathrm{V}_{\mathrm{g}}}
$$

where $\mathrm{V}_{\mathrm{i}}$ is the internal gas volume of the apple. Equations [2], [3], and [4] are combined to eliminate the unknowns, $\mathrm{C}_{\mathrm{i}}$ and $\mathrm{C}_{x}$ :

$$
\mathrm{C}_{2}=\mathrm{C}_{\mathrm{l}} \cdot \frac{\mathrm{V}_{\mathrm{i}} \cdot \mathrm{V}_{\mathrm{o}}}{\mathrm{V}_{\mathrm{g}}^{2}} \cdot\left(1-\mathrm{e}^{-\mathrm{k} . \mathrm{t}}\right)^{2}
$$

The efflux rate constant $(\mathrm{k})$ can be calculated by rearranging this equation:

$k=\frac{-1}{1200} \cdot \ln \left[1-\sqrt{\frac{C_{2}}{C_{1}} \cdot \frac{V_{g}^{2}}{V_{i} \cdot V_{o}}}\right]$

$\mathrm{R}$ was calculated from $\mathrm{k}$ following Eq. [8] of Cameron and Yang (1982). The extra terms correct for the smaller ratio of container to fruit volume than in the original derivation:

$$
\mathrm{R}=\frac{\mathrm{A}}{\mathrm{k}} \cdot \frac{\mathrm{V}_{\mathrm{g}}}{\mathrm{V}_{\mathrm{i}} \cdot \mathrm{V}_{\mathrm{o}}}
$$

These equations required estimates of fruit surface area (A), and various volume terms $\left(\mathrm{V}_{\mathrm{i}}, \mathrm{V}_{\mathrm{g}}\right.$, and $\left.\mathrm{V}_{\mathrm{o}}\right)$. Area was calculated from fruit volume (V), assuming that an apple approximates a sphere:

$$
\mathrm{A}=4.836 . \mathrm{V}^{0.667}
$$

Intercellular spaces account for most of the internal gas volume in fruits, but some gas is present in solution in cell fluids. The contribution of dissolved gas is defined by the partition coefficient between gas and liquid phases. The water/air partition coefficient for ethane was found to be $\approx 0.05$ (by volume); the value of 0.1 , reported by Cameron and Yang (1982) is close to the partition coefficient of ethylene, 0.11 (Howarth et al., 1985). The partition coefficient for apple cell contents was assumed to be the same as for water, and $1 \mathrm{~g}$ of apple juice, occupying 0.944 $\mathrm{ml}$ (Hatfield and Knee, 1988), would contain $0.0472 \mathrm{ml}$ ethane $(0.05 \times 0.944)$ with pure ethane in the gas phase. Thus, the internal gas volume of an apple is defined by the equation:

$$
\begin{array}{r}
\mathrm{V}_{\mathrm{i}}=\mathrm{V}-\mathrm{W} \cdot(0.944-0.047)= \\
\mathrm{V}-\mathrm{W} \cdot 0.897
\end{array}
$$

The internal gas volume of eight apples (ranging from 35 to $94 \mathrm{ml}$ ) was estimated by this volumetric method and from the concentration of ethane at equilibrium after efflux as described by Cameron and Yang (1982). Linear regression analysis of the data showed a correlation coefficient of 0.99 , a slope close to unity (0.996), and an intercept close to zero (volumetric method $=2.47 \mathrm{ml}$, when efflux method $=0$ ).

Finally, the volume of gas phase external to the apple $\left(\mathrm{V}_{\mathrm{o}}\right)$ is the difference between container volume and fruit volume (1000 V). Internal gas volume must be added to this to find the total gas volume in the experimental system:

$$
\mathrm{V}_{\mathrm{g}}=10000-\mathrm{V}+\mathrm{V}_{\mathrm{i}}
$$

The equivalence of the new method with the procedure of Cameron and Yang (1982) was tested by using both methods to estimate the diffusive resistance of 22 individual apples of various cultivars (Fig. 1). The new method resulted in lower values of $R$ than the Cameron and Yang (1982) method. A quadratic regression showed a slightly better fit $(r=0.856)$ than a linear regression $(r=$ $0.821)$, suggesting a curvilinear relationship. The highest resistance values and greatest deviation between the methods were shown by 'Granny Smith' apples. Only a small fraction of the ethane diffused in and out of these apples in the 20-min incubation periods. Extending the incubation times to 45 min for loading and unloading gave a mean value for $R$ of $37,000 \mathrm{~s} \cdot \mathrm{cm}^{-1}$, which was closer to that observed using the Cameron and Yang (1982) method (Table 1). This led to an investigation of the effect of incubation time on $\mathrm{R}$ as measured by the new method. There was a tendency for $\mathrm{R}$ to increase with time and this was more pronounced for 'Granny Smith' apples than for the other apples tested (Table 1).

These inconsistencies could result from departures from the initial premise of Fick's First Law: diffusion should occur from a single compartment through a thin barrier at its surface. The rapid exchange of ethane in a second compartment (lenticel cavities or skin) of the apple surface would add to the amount diffusing from within the apple. This would lower the estimate of diffusive resistance in the new method, particularly for short incubation times. The Cameron and Yang (1982) method would not be affected. Alternatively, slow diffusion inside the apple would result in increasing estimates of resistance with longer incubation times. In the new method, estimates of $\mathrm{R}$ should approach the value for skin resistance as incubation time is reduced. The method of Cameron and Yang (1982) would result in an estimate of skin resistance plus a component of internal resistance. Acceptance of Fick's First Law as a model rests on the agreement between predicted and actual internal gas concentrations (Burg and Burg, 1965) and linearity when an appropriate function of efflux is plotted against time (Cameron and Yang, 1982). These are not rigorous criteria and the methodology may not permit a decisive test. It is worth noting that Brandle (1968) concluded from direct measurements of oxygen concentrations in different regions of apple fruit that there were internal barriers to diffusion.

In further tests of the new method with 'Granny Smith' apples, ethane was measured at 5-min intervals in a 20-min efflux period. An iterative procedure was used to calculate concentrations at zero and infinite time, which gave the best fit to a Fick's Law model. The zero time value could represent 
a rapid efflux component. Subtracting this concentration from the estimate of $\mathrm{C}_{2}$ resulted in a $12 \%$ higher estimate of $\mathrm{R}$ than using the uncorrected $\mathrm{C}_{2}$. In these experiments, resistance by the method of Cameron and Yang (1982) was also $12 \%$ higher on average than by the new method.

The resistances of nine individual 'Cox' apples were estimated twice by each method, Analysis of variance gave estimates of the coefficient of variation for the Cameron and Yang (1982) method of $6.6 \%$ and for the new method, $11.1 \%$. The new method was used in a factorial experiment on the effects of maturity, season, and orchard factors on 'Cox' apples. For each treatment the resistance was measured twice for each fruit in two five-apple samples. A coefficient of variation of $13.2 \%$ was estimated for these means. We demonstrated, with better than 99\% confidence, that resistance declined as harvest date was delayed and that there were seasonal and orchard effects (Knee et al., 1990). The new method of measuring diffusive resistance is suitable for experiments involving many fruits. The incubation time of $20 \mathrm{~min}$ is appropriate for many apple cultivars but should be increased when $\mathrm{R}$ exceeds about 20,000 $\mathrm{s} \cdot \mathrm{cm}^{-1}$ Correspondence between estimates of resistance by the established procedure (Cameron and Yang, 1982) and the new method should be verified before use on other cultivars and commodities.

\section{Literature Cited}

Banks, N.H. 1985. Estimating skin resistance to gaseous diffusion in apples and potatoes. J. Expt. Bot. 36:1842-1850.

Brandle, R. 1968. Die Verteilung der Sauerstoffkonzentrationen in fleischigen Speicherorganen (Apfel, Bananen und Kartoffelknollen). Ber. Schweiz. Bot. Ges. 78:330-364.

Burg, S.P. and E.A. Burg. 1965. Gas exchange in fruits. Physiol. Plant. 18:870-874.

Cameron, A.C. and S.F. Yang. 1982. A simple method for the determination of resistance to gaseous diffusion in plant organs. Plant Physiol. 70:21-23.

Dover, C.J. 1985. Commercial scale catalytic oxidation of ethylene as applied to fruit stores, $\mathrm{p}$. 373-383. In: J.A. Roberts and G.A. Tucker (eds.). Ethylene and plant development. Butterworths, London.

Hatfield, S.G.S. and M. Knee. 1988. Effects of water loss on apples in storage. Intl. J. Food Sci. Technol 23:575-583.

Howarth, C.J., A.R. Smith, and M.A. Hall. 1985. Ethylene binding in Phaseolus vulgaris L. development. Butterworths, London.

Knee, M. 1990. Fruit metabolism and practical problems of fruit storage under hypoxia and anoxia, p. 229-243. In: M.B. Jackson, D.D. Davies, and H. Lambers (eds.). Plant life under oxygen deprivation. SPB Academic Publishing, The Hague, Netherlands.

Knee, M., S.G.S. Hatfield, and W.J. Bramlage. 1987. Response of developing apple fruits to ethylene treatment. J. Expt. Bot. 38:972-979.

Knee, M., S.G.S. Hatfield, and D. Farman. 1990. Sources of variation in firmness and ester content of 'Cox' apples. Ann. Applied Biol. 116:617-623. 